\title{
A CASA FAMILIAR RURAL E A POLÍTICA DE EDUCAÇÃO DO CAMPO: HISTÓRIA DE RESISTÊNCIA DO MOVIMENTO SOCIAL NO OESTE PARAENSE
}

\author{
Glez Rodrigues Freitas Bentes ${ }^{1}$ \\ Anselmo Alencar Colares ${ }^{2}$ \\ Universidade Federal do Oeste do Pará/UFOPA
}

\begin{abstract}
RESUMO
O presente estudo busca compreender o processo histórico de criação da Casa Familiar Rural de Santarém e sua relação com a constituição do movimento social do campo do Oeste Paraense pela sua efetivação como política educacional do campo. Reconstituímos as discussões iniciais de articulação e criação do Movimento social do campo no Oeste Paraense, e sua atuação e participação na proposição das políticas públicas, sobretudo às educacionais do campo. A partir da análise de documentos oficiais, registros informais das lideranças do movimento social do campo e entrevistas junto a esses sujeitos, nos permitiram identificar nas lutas de resistência e emancipação dos sujeitos do campo suas estratégias de mobilização na constituição do poder local. Concluímos, portanto que a história da CFR-STM integra e se confunde com a história do movimento social do campo em Santarém e Região Oeste Paraense, e que, por meio da sua capacidade criativa, este movimento, estrategicamente se apropria de espaços coletivos de diálogos na construção de políticas de educação do campo, se reinventando a partir de suas limitações internas, gradativamente, ressurgindo como um espaço de articulação da sociedade civil, em uma estratégia conceituação de territorialidade e de resistência.

Palavras-chave: Casa Familiar Rural; Política Educacional do campo; Movimento Social.
\end{abstract}

\section{THE RURAL FAMILY HOUSE IN SANTAREM AND THE RURAL EDUCATION POLICIES: RESISTANCE HISTORY OF SOCIAL MOVEMENT IN WESTERN OF PARÁ.}

ABSTRACT

This study aims to understand the historical process of creation of Santarém Rural Family House (CFR-STM) and its formation in the social movement of the Paraense Western rural and its struggle for consummation as an educational policy rural. We rebuilt the initial discussions of articulation and creation of the Social movement rural in western Pará, and its performance and participation in the proposition of public policies, especially the educational field.From the analysis of official documents, records of informal social movement leaders from the rural and interviews with these subjects, allowed us to identify the resistance struggles and emancipation, their mobilization strategies in the constitution of local power. Therefore, we conclude that the history of CFR-STM integrates and is confused with history of the social movement of the rural in Santarem and West Region Pará, and that through their creative capacity this movement strategically appropriates collective spaces dialogues in the construction of rural education policies, reinventing itself from its internal constraints, gradually emerging as a civil society joint space, a strategy concept of territoriality and resistance.

Keywords: Social Movement. Rural Family House. Rural Educational Policy. 


\section{Introdução}

As Casas Familiares Rurais (CFRs) e/ou Escolas Famílias Agrícolas (EFAs) são experiências construídas pelo movimento social do campo como alternativa para o acesso à educação adequada ás necessidades dos jovens do campo e de resistência ao modelo urbanocêntrico excludente. São originárias na Europa, em 1935, na França, a partir da experiência das Maisons Familiales Rurales ou Casas Familiares Rurais e nos anos de 1960-1962, na Escola Família Agrícola (EFA), na Itália, por meio da iniciativa de famílias de agricultores que junto às entidades católicas, demandavam uma educação para seus filhos, diferenciada daquela oferecida pela escola tradicional. (NOSELLA, 2014).

Tais experiências propõem uma concepção filosófico-metodológica, denominada de Pedagogia da Alternância, compreendida como um novo projeto pedagógico que se organiza pela alternância de tempos formativos em que teoria e prática caminham juntas, no sentido de compreender a realidade e de intervir nela. Visam à formação integral e a transformação social na qual o sujeito do campo se insere e estão articuladas entre si através da rede de Centros Familiares de Formação por Alternância (CEFFA), compostas Associações Regionais de CFRs - ARCAFAR.

A Pedagogia da Alternância é atualmente uma das mais reconhecidas e amplas estratégias da educação do campo, que tem se destacado nos últimos anos como nova modalidade educacional presente na realidade brasileira, permitindo impactos $\mathrm{e}$ potencialidades frente à construção de uma sociedade justa e democrática. Busca envolver o jovem do campo, a sua família, a instituição de ensino, a comunidade e a realidade do campo nos processos de ensino-aprendizagem. Nesta experiência, a organização camponesa assume a gestão administrativa e pedagógica constituída na modalidade de Associação de Agricultores, com fins jurídicos, financeiros e administrativos, com a participação efetiva dos pais de alunos na gestão (SILVA, 2003, NOSELLA, 2014).

A respeito da origem da Pedagogia da Alternância no Brasil, destacamos o modelo pioneiro, desenvolvida pelo Movimento Educacional Promocional do Espírito Santo MEPES, a partir de 1969, estudado por Paolo Nosella (2014), o qual influenciou e serviu de referência para a criação de outras experiências de alternância em nosso país, inclusive a CFR de Santarém.

Vimos que, a "Educação do Campo" é um conceito que surge no âmbito das lutas dos movimentos sociais e sindicais do campo articulados ${ }^{3}$, a partir da década de 1990 contra a problemática da exploração provocada pelo sistema capitalista à população do campo no Brasil, compreendendo suas especificidades e contribuições ao processo mais amplo de educação na perspectiva do mundo globalizado.

Assim, a educação do campo segundo Nosella (2014, p.259) "nomeia um fenômeno da realidade brasileira atual, protagonizado pelos trabalhadores do campo e suas organizações, que visa incidir sobre a política da educação desde os interesses sociais das comunidades camponesas". A exploração provocada pelo sistema capitalista atinge a população do campo, que por sua vez, articula-se com os diferentes processos de luta social, desenvolvidos pelos movimentos sociais e sindicais, buscando enfrentá-la. Descortinando-se um processo histórico do Movimento de Educação do Campo no Brasil e de sua influência na constituição das políticas públicas nessa área.

O presente estudo analisa a experiência da Casa Familiar Rural de Santarém, a partir da necessidade de compreender como o movimento social do campo se constituiu e se relaciona para a criação da CFR-STM, e posteriormente, ao longo da implantação e efetivação desta experiência, como se dá o contato com o poder estatal. Nossa pesquisa surgiu da relevância da CFR-STM - nascida em 1999 - por dentro de um fórum do movimento social, representativo de populações rurais. Sendo que foi a primeira no 
contexto regional do Baixo Amazonas, Oeste paraense, a se articular e demandar políticas de acesso à educação para jovens das comunidades rurais; tendo em vista a emancipação política e melhoria na produção familiar rural nesta região.

É nesta perspectiva, que desenvolvemos este estudo acerca da Casa Familiar Rural de Santarém, e analisamos esta experiência, uma vez que ela tem sido apontada no conjunto dos debates acadêmicos e dos movimentos sociais como uma alternativa educacional na formação dos sujeitos do campo.

A seguir um breve resgate do movimento social do campo em Santarém, observando a percepção dos seus sujeitos, destacando algumas transformações ocorridas durante o percurso, situando o processo que culminou na criação e implantação da CFR/Santarém e o característico envolvimento desta experiência educacional do campo com o contexto do movimento social local.

\section{O contexto do surgimento do movimento social do campo e o Fórum da Produção Familiar em Santarém}

No fim da década de 1980 e meados da década seguinte, as comunidades eclesiais de base (CEB's), coordenadas pela Diocese de Santarém por meio de suas áreas pastorais, mobilizaram um processo de discussão pela melhoria do preço da farinha, motivando a criação de um Fórum de instituições não governamentais, incentivado pelo trabalho de Organizações não Governamentais e pela atuação de instituições representativas dos trabalhadores do campo, como o Sindicato dos Trabalhadores e Trabalhadoras Rurais (STTR) e Pastorais Sociais. Este Fórum conduziu ações que levaram à discussão da educação de jovens rurais e à criação da primeira Casa Familiar Rural de Santarém CFR/STM. (BENTES, 2015, snt ${ }^{4}$ ).

Desse modo, as primeiras discussões sobre o enfoque da pedagogia da alternância em Santarém surgiram por volta de 1994, no contexto das organizações dos produtores familiares na região dos rios Tapajós e Arapiuns.

As informações históricas contidas neste tópico remontam as primeiras discussões para a articulação e criação de um Fórum interinstitucional de debate sobre a Produção Familiar em Santarém. Foram conseguidas por meio de caderno de notas de reuniões de Área Pastoral, datado de dezembro de 1994 a fevereiro de 1995, feitas por lideranças do movimento social local e regional, membro e articulador deste Fórum. Desta forma, a existência de um "Fórum da Agricultura", inicialmente concebido em 1994, teve origem com a articulação de um conjunto de instituições não governamentais de assessoria e entidades representativas de trabalhadores rurais em Santarém, além de grupos de pastorais sociais ligados à Igreja Católica que se reuniram para alcançar objetivos ligados à agricultura familiar.

Este Fórum, de caráter interinstitucional e informal, ou seja, sem personalidade jurídica, atuou no período de 1994 até o ano de 2000 e, segundo registros informais das lideranças da época, esta mobilização em Santarém foi inicialmente incentivada por um movimento que ficou conhecido como "Movimento pelo preço da farinha" ocorrido em meados de 1994 e liderado por Comunidades Eclesiais de Base (CEB's) vinculadas à Igreja Católica, em diversas áreas rurais do município de Santarém. (CODETER-BAM, $2015^{5}$ ):

O registro acima revela que, desde as primeiras mobilizações ${ }^{6}$, houve um intenso processo de articulação e debates, diante da insatisfação com a situação de abandono dos trabalhadores da pequena agricultura no município de Santarém.

Percebemos que, assim como ocorreu na história que precedeu a criação da CFR do município de Gurupá, mesorregião do Marajó, Belém (Pará), estudado por Benedita 
Magalhães (2009); em Santarém, ocorreu também forte presença da Igreja Católica através das CEB's com sua prática da Educação Popular. Neste aspecto, Brandão (2002, p.86) considera esta educação popular "como uma forma de educação política cuja definição é qualificada por uma clara conotação classista que a diferencia de outras formas de educação não formal". Tal prática revelou-se também nesta região aqui mencionada, importante ação mobilizadora e incentivadora da identidade cultural de uma população rural específica, capaz de motivar o seu potencial de articulação, como sujeitos determinantes de transformação social.

Desse modo, foram decisivos os processos iniciais de mobilização, considerados precedentes à constituição do Fórum da Produção Familiar Rural de Santarém, pois com base ainda em registros informais, aqueles momentos de reunião levaram a um contato maior com as entidades, sobretudo do meio governamental. O que, segundo registros, "viria a facilitar ainda mais o trabalho que estavam pensando". (CADERNO, 1994, snt).

A perspectiva deste movimento era a questão da produção e mercado da agricultura familiar. A esse respeito, o presidente do Sindicato dos Trabalhadores Rurais em Santarém, na época ${ }^{7}$, ao relembrar as principais bandeiras de luta deste movimento, disse que a principal discussão se dava em torno de três temáticas: produção, beneficiamento e comercialização da produção. Conforme podemos constatar no depoimento a seguir.

\footnotetext{
Resultou em um debate muito forte dentro do Fórum, esses três eixos: a produção que teria que ter uma assistência técnica pra melhorar (...) a questão produtiva, os conhecimentos técnicos por meio de cursos, o acesso às estradas e aos ramais. Na comercialização eram as feiras, pois as feiras resultando nas feiras que existem hoje em Santarém como a Associação de Produtores; os eventos de exposição de produtos. E o beneficiamento que trata da questão do mercado, do melhor preço. (Presidente do STTR/STM na época de criação da CFR-STM, entrevistado em 22.04.2015)
}

Acreditavam os primeiros participantes desse movimento, que as entidades teriam a responsabilidade de subsidiar os trabalhadores com informações necessárias sobre as grandes questões que as envolviam. Nesse sentido, tinham a definição de que aquele fórum das entidades deveria ser organizado na perspectiva dos trabalhadores, pois não aceitavam, em nenhuma hipótese que fosse criado mais um espaço de reuniões e não se buscasse solução para os problemas enfrentados pelos trabalhadores.

Ainda a respeito das demandas de criação do Fórum da Produção Familiar Rural de Santarém, o então presidente do STTR-Santarém informou que:

Esse fórum tem sua origem em meados dos anos 1990 (...) e foi uma necessidade das instituições representativas e as instituições de assessoria sempre estarem se relacionando. Acontece que naquele momento era de encarar os desafios de se juntar numa articulação de uma forma, e denominar isso aí para que a gente possa tá discutindo as nossas estratégias, e onde cada organização desenvolva o seu papel dentro da sua área de atuação. (ENTREVISTA)

Tal depoimento reforça a intenção de articulação e a necessidade de ação integrada entre as instituições representativas dos trabalhadores e as instituições de assessoria, como eram denominadas as organizações não governamentais que atuavam na região culminando na criação do Fórum da Produção Familiar Rural de Santarém. 
Segundo ainda registros informais de 1994 da referida reunião de área pastoral, acreditavam as lideranças da época que para que aquele Fórum fosse criado na perspectiva dos trabalhadores, era necessário "ter clareza do que a gente quer e para onde queremos levar essa discussão". Aquele movimento entendia que os trabalhadores não podiam mais relacionar-se com o governo de maneira individual, sendo preciso articular as ações dos trabalhadores visando organizar o relacionamento com as instâncias governamentais. (CADERNO, 12/12/1994, snt)

Avaliavam que o trabalhador devia superar a sua condição de espectador e passar à condição de interlocutor, pois não admitiam mais ir apenas para espaços de discussão, mas seria necessário "intervir na realidade e formatá-la a partir de seus interesses, na perspectiva de pequenos agricultores". Refletia-se sobre como estabelecer uma relação com o poder público de maneira que "não fossem meros respaldadores das ações do governo, mas ocupando o papel de proponente das ações governamentais" (CADERNO).

Como alternativa para a solução dos problemas enfrentados pelos trabalhadores na formulação de políticas públicas voltadas aos interesses do pequeno agricultor daquela época, conforme ainda este registro histórico de reunião, concluíram que, sem perder a autonomia, deviam buscar: a) "maior articulação entre as entidades de apoio (assessoria não governamental) e entidades de trabalhadores" (associações e sindicatos); b) "ampliar a base de apoio a fim de respaldar a ação reivindicatória do movimento dos trabalhadores" e; c) "manter os trabalhadores informados sobre as grandes questões relacionadas aos problemas enfrentados no cotidiano do agricultor familiar (questão fundiária, assessoria técnica, projetos, etc.)" (CADERNO).

Aquele grupo de participantes então refletiu sobre qual era o projeto que tinham como pretendiam viabilizá-lo e a quem dirigi-lo. Neste aspecto, foi encaminhado como planejamento, a realização de um Seminário Regional de debate sobre a produção e comercialização e sobre o papel das ONGs e do Estado neste processo. A sistematização das propostas foi organizada do seguinte modo:

Figura1 - Quadro de sistematização das propostas encaminhadas (Área Pastoral 04)

\begin{tabular}{|c|c|}
\hline Ações mais amplas & Ações Imediatas \\
\hline 1. Seminário sobre produção e & 1. Melhoria dos ramais \\
comercialização & 2. Legalização das terras \\
2. Congresso de Pequenos & 3. Assessoria técnica \\
$\begin{array}{l}\text { agricultores do Baixo Amazonas } \\
\text { sobre Produção e }\end{array}$ & 4. Poços para abastecimento d’água \\
comercialização. & 5. Lerificar em quais comunidades)
\end{tabular}

Fonte: Elaborado por participantes conforme registro de reunião de 12/12/1994.

Para os problemas imediatos, os participantes planejaram naquela ocasião, buscar parcerias, como por exemplo, o então campus da Universidade Federal do Pará (UFPA), em Santarém. O propósito era discutir temáticas como a água, tendo em vista tratar questões sobre agricultura. E com a EMBRAPA, SAGRI e EMATER planejar ações diretamente voltadas às atividades agrícolas. Decidiram também, enviar ao INCRA um requerimento solicitando esclarecimentos sobre o processo de titulação de terras, sendo convidados a participar em próxima reunião. O Seminário sobre produção e comercialização, foi previsto para o período de 27 a 30 de abril de 1995 em espaços cedidos pela Igreja católica, na perspectiva de ter presente todos os representantes de organizações que trabalhassem com a agricultura, representantes de comunidades ou de área para discussão e busca de mercado para a agricultura familiar no município de Santarém ${ }^{8}$. 
O referido "Congresso de Pequenos agricultores do Baixo Amazonas sobre Produção e Comercialização" buscou alcançar os seguintes objetivos:

Discutir a realidade da agricultura na região, buscando conhecer os trâmites do mercado consumidor, a organização da produção, armazenamento e venda.

Conhecer as tendências do mercado consumidor, apontando alternativas de venda por melhores preços da produção regional do pequeno agricultor.

Discutir a pequena produção no relacionamento com a grande produção na busca de melhores preços, qualificando a produção familiar e o estímulo ao homem do campo.

Discutir mercado e produção na perspectiva do pequeno agricultor, levando em consideração a melhoria da qualidade de vida do trabalhador rural.

Discutir ações conjuntas de processos organizados de pequena produção, tendo em vista o melhoramento da produção, abertura de mercado e busca de melhores preços.

Discutir projetos alternativos na perspectiva da produção familiar, aumento da produção, assessoramento técnico, busca de mercado consumidor e valorização da produção. (CADERNO, 12/12/1994, snt)

Percebemos com a descrição dos objetivos acima, que a característica da forte relação com os interesses econômicos voltados ao contexto das atividades agrícolas do homem do campo, norteou a demanda de criação e funcionamento daquele Fórum interinstitucional, influenciando também as demandas dos trabalhadores do campo dessa região. Neste aspecto, afirma Hofling (2001) que em uma sociedade dividida em classes, a primeira política que o Estado privilegia é a econômica, e não, as sociais, sendo tais políticas, orientadas por um modo de produção (capitalista); instalando-se o Estado, dentro destas características de responder primeiro pelas questões econômicas.

Ainda a respeito dos antecedentes do movimento do campo em Santarém, identificamos que para dar prosseguimento aos encaminhamentos deste momento de debates, uma comissão de agricultura foi escolhida ${ }^{9}$, com a finalidade de articular as demais instituições ainda não envolvidas para que viessem participar das ações mais amplas que foram planejadas, como o Seminário e o Congresso de agricultura, bem como informadas sobre os resultados das últimas discussões, naquela ocasião. Para tanto, esta comissão decidiu elaborar e enviar uma carta às entidades, para solicitar que estas enviassem seu plano de trabalho com objetivo de ser incorporado em um planejamento geral.

Entendemos, até aqui, que os vários encontros propostos foram a culminância para a articulação e criação de um Fórum que seria composto por diversas instituições de assessoria não governamentais, bem como por órgãos públicos. Registra-se neste momento, o nascimento do que consistiu em um Fórum da Produção Familiar em Santarém.

Com base nas informações contidas nestes registros, pudemos constatar que havia já neste período (fim do ano de 1994 e início de 1995) um interesse por parte das instituições de base comunitária e de assessoria e apoio às comunidades que constituíram esta mobilização para a criação deste Fórum, como espaço de articulação interinstitucional entre sociedade civil organizada e instituições governamentais, representativas do Estado. Pois havia o entendimento, por parte destas, que as suas reivindicações e lutas pela defesa do trabalhador do campo, não se concretizariam se continuassem isolados ou 
desarticulados de um processo de diálogos mais ampliado. Materializando-se desse modo, a constituição informal e interinstitucional do Fórum da Produção Familiar de Santarém.

A seguir, relacionaremos nosso objeto aos aspectos globais, pontuando a contextualização de alguns elementos conjunturais sociopolíticos, ambientais e econômicos, destacados em registros orais e documentais, dentre outras fontes; as quais possivelmente interferiram na realidade local na época da implantação da CFR-STM.

\section{A conjuntura socioeconômica e política nacional e local}

O contexto socioeconômico e político, no âmbito das políticas neoliberais, sobretudo na década de 1990, quando de acordo com Frigotto (2004), passam a dominar o ideário neoliberal da globalização, influenciou o movimento social do campo. Deste modo, se faz necessário traçarmos um breve panorama do contexto da implantação e consolidação do projeto neoliberal em nosso país, a partir da década de 1980, com o então presidente Fernando Collor, prosseguindo com o governo Itamar, tendo o ápice no governo de Fernando Henrique Cardoso, que se tornou o principal representante desta proposta política.

No esforço intelectual de sintetizar brevemente a política de Fernando Henrique Cardoso (FHC), Alentejano (2004) destacou como características centrais de sua política neoliberal: i) o aumento da dependência externa; ii) a privatização realizada à custa do Estado; iii) a prioridade dada ao sistema financeiro; iv) o aumento das desigualdades sociais, resultante do aumento dos lucros das empresas e da queda da renda dos trabalhadores e; v) a explosão do desemprego.

No que se referem à área rural, estes aspectos centrais que deu à política de FHC um caráter antipopular, definido como neoliberal, provocou um verdadeiro desmonte resultando na redução de recursos públicos destinados à agricultura, sobretudo ao crédito rural e na perda de espaço político-econômico dos setores da burguesia agrária.

No entanto, as políticas neoliberais e a política agrícola do governo de FHC, não feriram apenas os interesses econômicos da burguesia agrária. Também foram incompatíveis com a pequena produção agrícola, chegando mesmo a desprezar a pequena produção familiar.

Como consequência, foram acentuadas as condições para a concentração fundiária. O modelo da grande produção passava a receber os recursos públicos de financiamento agrícola, enquanto que os preços dos produtos produzidos pelos agricultores familiares apresentavam queda vertiginosa. Desse modo, um projeto de natureza tão divergente aos interesses das classes trabalhadoras, sobretudo, as do campo, não podia ter entre seus elementos uma política de reforma agrária. (COLETTI, 2006; ALENTEJANO, 2004).

O crescimento em nosso país da luta pela terra ocorreu, sobretudo, a partir de meados da década de 1990, durante o governo FHC. Relacionado diretamente a esse fato, está o crescimento do Movimento dos Trabalhadores Rurais Sem Terra (MST), que se transformou na maior expressão política da luta pela terra e pela reforma agrária e no mais importante movimento social de oposição ao projeto neoliberal no Brasil. Com sua ideologia anticapitalista, este movimento permitiu a resistência à hegemonia neoliberal naquela década, indicando que a luta econômica pela terra estava diretamente ligada à luta política pela reforma agrária e, sobretudo à luta contra as políticas neoliberais.

Nesse ínterim, o governo FHC mudou sua tática de enfrentamento e de criminalização das ações do MST e demais movimentos de luta pela terra, numa clara tentativa de reverter o quadro politicamente desfavorável do ponto de vista da questão agrária, em que foi posto em seu primeiro mandato. Resultado da combinação da contra ofensiva dos movimentos sociais rurais - especialmente o MST, mas também a CONTAG 
e seu "Grito da Terra" e da crescente pressão internacional, diante do episódio do "Massacre de Eldorado dos Carajás"10, símbolo da violência do campo e da ausência de política de reforma agrária no Brasil

Este Governo neoliberal escolheu outros campos de disputa, resultando num efetivo reposicionamento do debate acerca do tema no país, mas cujo pano de fundo foi sempre a reafirmação do domínio do campo brasileiro pelo capital.

\section{Os Reflexos das políticas neoliberais na realidade do campo em Santarém no Oeste Paraense $^{11}$}

A análise de conjuntura, pelas lideranças comunitárias em 1995, trazia a percepção de que o mundo está interligado por acontecimentos que, mesmo bem distantes, afetam a vida das pessoas em geral, em qualquer lugar que estejam. Ou seja, havia a compreensão das lideranças de que o que acontecia na comunidade não dizia respeito somente ao contexto local, pois estava interligado à situação regional, nacional e mundial. E que decisões tomadas pelo poder público, e por organismos internacionais, atingiam diretamente a vida do trabalhador. Daí era importante conhecer não somente os efeitos dessas decisões, mas conhecer os responsáveis, as causas e as formas de enfrentamento.

O contexto político e econômico nacional foi relacionado com a realidade da conjuntura política e econômica do campo local na década de 1990 - época em que o movimento do campo se articulava para a criação da CFR-STM. Fizeram o exercício de relacionar acontecimentos das comunidades aos reflexos da política econômica no âmbito federal no período de 1992 a1994, governo do então presidente Itamar Franco, que teve Fernando Henrique Cardoso (FHC), como Ministro da Fazenda, o qual criou e implantou no ano de 1994, o Plano Real. Este Plano se propôs a combater a inflação, tendo como base, conforme registros escritos das lideranças, mudanças da moeda (de cruzeiro real para real); reservas cambiais (para permitir o equilíbrio da moeda através da compra dos dólares que entravam no país); taxa de juros altos; valorização cambial (14\% do real sobre o dólar); abertura do mercado para importação (forçando a caída de preços da mercadoria produzida internamente) e privatizações para arrecadação financeira.

A política neoliberal, comandada pelo Plano Real, levou a população à economia informal em uma situação de desespero e pânico. Para aquele grupo de lideranças do campo em Santarém, o plano Real não passava de uma "falácia da não inflação, que serviu para "hipotecar" e impulsionar a candidatura de FHC à Presidência da República, para elegê-lo no primeiro turno das eleições daquele ano". (CADERNO, 1995, snt).

Transferindo essa questão de ordem política nacional (Plano Real), bem como as políticas neoliberais de modo geral, para a realidade econômica local das comunidades, constatamos que os trabalhadores percebiam como falsa impressão de melhoria na vida, pois inicialmente havia o anúncio do equilíbrio da inflação, mas, no entanto, camuflava uma dificuldade no cálculo do valor de seus produtos, devido à troca da moeda. Sentiam que o seu poder de compra havia diminuído, embora a moeda nacional estivesse forte. Todavia, "o plano real (...) não melhorou a vida do trabalhador". E o trabalhador resistia com poucos recursos, valorizando o preço da farinha, principal produto comercializado. (CADERNO, 1995, snt).

Outra consequência da política do então presidente FHC, na avaliação destas lideranças comunitárias, foi o corte de recurso na saúde e na educação pública, atingindo diretamente a classe trabalhadora. Demonstrando na prática por ações (políticas) voltadas aos interesses da classe média/alta. Além de aceitar as doutrinas ditadas pelo Fundo Monetário Internacional - FMI e a privatização de empresas estatais como exigência do 
fundo monetário, FHC revelou, na opinião daquelas lideranças, que "todas as vezes que tiver que tomar posição, seria sempre da classe dominante". (CADERNO, 1995, snt).

As lideranças do campo identificaram ainda outros fatos marcantes nas diversas regiões do município, que nos ajudam a compreender a realidade daquela época. Com a aplicação de metodologia de divisão de grupos, foram convidadas a pensar sua realidade por regiões de origem: Arapiuns e Lago Grande, Tapajós e Planalto (Eixo Forte e Moju).

Na região ribeirinha (Arapiuns e Lago Grande) foi destacada a "chegada" do Plano Real, como elemento que surpreendeu as pessoas, devido falta de compreensão a respeito. Nesta região, foi identificada também, segundo lideranças locais da época, a implantação do ensino de $1^{\circ}$ grau e de posto de saúde, além da existência de delegacia sindical como sinal de presença do Sindicato dos Trabalhadores Rurais; sendo também forte neste período, a discussão em torno do processo de legalização das terras e a organização de associação em torno de projetos econômicos alternativos.

Na região ribeirinha do Tapajós, os fatos mais destacados foram o significado do projeto de implantação de transportes comunitários ${ }^{12}$ na vida dos moradores das comunidades na época. Deste modo, os registros demonstraram que apesar das dificuldades de administração, este projeto representava a construção de qualidade de vida no campo, por ter possibilitado a libertação dos moradores ao servir como "amenizadores aos preços de passagens", sobretudo em relação aos proprietários de embarcações.

No entanto, aquele grupo de coordenadores reconhecia que havia ainda "imaturidade na condução do processo", pois esta experiência segundo eles, ainda não tinha possibilitado uma visão ampla do processo. Outro fato relatado foi o "aparecimento" de pessoas de outros Estados interessados na exploração madeireira, levando a instalação de uma empresa madeireira que invadiu a região do Tapajós.

Avaliaram também naquela ocasião, que as comunidades não estavam reagindo diante do saque da madeira na região e para tanto, foi planejado uma Assembleia naquela comunidade para discussão do problema das terras na região Tapajós. Além disso, constataram que as eleições de 1994 representaram um "fracasso para as organizações populares", devido à derrota do Partido que as representava.

Em diversas regiões rurais do planalto santareno, por sua vez, os fatos destacados que retratavam a realidade da época foram, sobretudo, a invasão de moradores da cidade para apropriação das margens de igarapés para balneários. No que se referem à produção, os moradores do Moju, relataram que o preço da farinha estava desvalorizado e que não havia transporte terrestre para trazer a produção até a área urbana de Santarém, onde se encontrava (e ainda se encontra), o maior centro de compra do produto.

Outro reflexo da realidade vivenciada no início da década de 1990 foi o enfraquecimento do movimento jovem, devido sua atuação isolada de outros grupos locais, assim como o próprio Sindicato dos Trabalhadores Rurais. A possibilidade de um "trabalho novo", segundo moradores dessa região, estava voltada na expectativa de organização dos moradores em associações intercomunitárias que representassem as suas necessidades.

As falas descritas até aqui, revelam o cenário das principais atividades do campo, desenvolvidas em Santarém pelos diversos grupos locais nas diferentes realidades socioculturais daquele território e naquele espaço temporal da década de 1990, a partir dos tipos de ocupação agrícola. 


\section{O surgimento da Casa Familiar Rural de Santarém}

O Fórum da Produção Familiar de Santarém (FPFRS) foi o primeiro espaço coletivo de discussão no território do Baixo Amazonas ${ }^{13}$. Neste território, a educação de jovens moradores das áreas rurais por meio da pedagogia da alternância, surge apoiada nas ações de organização comunitária desenvolvidas de modo articulado inicialmente por este Fórum, o qual propiciou o debate a respeito desta proposta pedagógica própria à realidade do campo. De modo que, em 26 de abril de 1999 através da articulação deste Fórum, é criada a Associação da Casa Familiar Rural de Santarém - ARCAFAR/ STM, iniciando, a primeira experiência de educação do campo nos princípios da alternância nesta região. (ARCAFAR/SANTARÉM, 1999).

Destacamos também, ainda no que se refere à implantação da proposta de educação por alternância em Santarém, a iniciativa do Sindicato dos Trabalhadores e Trabalhadoras Rurais de Santarém (STTR), por ser a instituição representativa dos trabalhadores do campo, e por desenvolver na sua essência, uma ação política de defesa dos trabalhadores rurais no direito à terra e à educação.

Deste modo o STTR de Santarém, foi uma das instituições precursoras, ainda que isolada de articulação com a experiência pioneira no Brasil de formação por alternância. Aqui nos referimos à Escola Família Agrícola - EFA do Espírito Santo, modelo pioneiro no Brasil criado em 1968, estudado por Paolo Nosella (2014). Assim, antes desta experiência ser conduzida por este Fórum de articulação do movimento social, o STTR/Santarém foi o precursor desse debate e posterior à efetivação deste Fórum, presidiu suas ações, conforme apresentaremos a seguir.

\section{O Sindicato dos Trabalhadores e Trabalhadoras Rurais (STTR) e a CFR/Santarém ${ }^{14}$}

No ano de 1991, em Santarém, o movimento sindical mudou sua estratégia de ação e reivindicações para investir na organização das comunidades rurais através da criação de associações de produtores como instrumento legal do agricultor. No entanto, sem abandonar o movimento de luta pela melhoria na questão agrária e agrícola. Pois, de acordo com a opinião do então presidente, "o Sindicato foi o criador de todas essas lutas que já ocorreram sobre a defesa da terra", tais como as políticas fundiárias, como a implantação dos assentamentos, a luta em defesa dos créditos, e muitas outras conquistas, a exemplo, da luta do Sindicato junto com outras instituições pela criação de Resex ${ }^{15}$. Afirmando ainda que além da defesa da terra, a criação da CFR, foi uma importante conquista, sobretudo no avanço na educação do campo e qualificação profissional do agricultor. Reconhecendo que este Sindicato teve uma relação histórica muito expressiva em Santarém por todas as suas intervenções políticas representando o trabalhador do campo.

Segundo ainda este depoimento, o Sindicato foi a primeira instituição que iniciou o debate sobre a educação no campo em Santarém, quando viu a necessidade de uma formação para o jovem do campo. Conforme declarado a seguir pelo presidente do STTR/Santarém na época:

No início o Sindicato tomou sozinho a decisão em função de ter tomado conhecimento de uma experiência das Casas Familiares Rurais e das Escolas Famílias Agrícolas no Espírito Santo. Mas não lembro como foi a forma como se articularam na época, mas em 1992 e meados de 1993, que o Sindicato tomou conhecimento dessa experiência e decidiu então escolher dois jovens para se capacitarem. Um deles atua na articulação regional de CFRs em Altamira e o outro, atua em Santarém, mas já foi 
Secretário de Agricultura em outro município do Baixo Amazonas. (Liderança sindical, ex-presidente do STTR/STM)

Desse modo, este Sindicato assumiu a ida de dois jovens para a formação na Escola Família Agrícola - EFA do Espírito Santo, durante o tempo previsto de três anos, continuando a participar e atuar no movimento social do Fórum da Produção Familiar, buscando sempre como metas: a produção, o beneficiamento e a comercialização dos produtos. Com o retorno dos jovens, foi criada uma expectativa pela entidade de que "seria possível a implantação da Casa Familiar Rural em Santarém, não foi atendida", pois "eles (os jovens) não tiveram uma atuação significante, porque vieram mais preparados para atuar como técnicos e não para coordenar um processo". (ENTREVISTA, líder sindical)

Percebe-se nesse momento, que a ida dos jovens, pensada como estratégia de implantação de uma experiência educacional de alternância no campo, no entanto, não correspondeu à expectativa política e aos objetivos daquele Sindicato naquele momento. Tanto que a experiência da formação técnica adquirida por aqueles jovens não foi inserida como estratégia do trabalho sindical.

Neste sentido, o Sindicato, já integrando e presidindo o Fórum, percebeu que aquela articulação do movimento social, seria um importante espaço político para assumir essa frente de discussões. Reconhecendo, portanto, que as conquistas que vieram beneficiar o trabalhador da área rural no município foram resultados da luta sindical em conjunto com as demais instituições que compunham e compõem o movimento social por meio do Fórum da Produção Familiar em Santarém.

Neste aspecto destacamos a noção de cidadania vinculada aos movimentos sociais, como estratégia enfatizada por seus "interesses concretos e práticas concretas de luta e pela sua contínua transformação", respondendo "à dinâmica demandada pelos conflitos reais vividos pela sociedade num determinado momento histórico" (DAGNINO, 2002, p.107).

A pedagogia da alternância, portanto, surgiu como resultado da busca de alternativas, não somente como contraponto ao êxodo rural latente na região, sobretudo da juventude, mas como perspectiva de formação do jovem rural neste município, com base na estratégia da produção familiar face à precariedade da formação escolar no campo e da falta de alternativa para o jovem permanecer na propriedade da família, com qualidade de vida e dignidade (BENTES, 2015, snt).

\section{O Fórum da Produção Familiar Rural e as CFRs como estratégica de articulação territorial}

A articulação do Fórum da Produção Familiar Rural de Santarém e sua efetiva atuação consistiram em um importante espaço de debates e conquistas de políticas públicas para a região na década de 1990 até a primeira década do ano 2000. Conforme relatos de lideranças da época, relevantes discussões surgiram dentro deste Fórum, além da criação da Associação da s em 1999. Tais como o processo de criação da Reserva Extrativista Tapajós/Arapiuns ${ }^{16} \mathrm{e}$ as mobilizações reivindicatórias como a ocupação do INCRA, resultando em negociação de recursos vultosos para investimento em assentamentos rurais, também em 1999, foram conquistas atribuídas a este Fórum.

Percebemos nesta dinâmica territorial da região do Baixo Amazonas - BAM, expressivas interações entre os movimentos sociais e as políticas públicas em torno da agricultura familiar e do desenvolvimento rural.

A partir das intervenções retratadas anteriormente, com a participação efetiva do movimento social em Santarém, entendemos que as políticas são conduzidas pelo Estado, mas ocorrem, sobretudo, estimuladas pela mobilização da sociedade civil. No entanto, as políticas públicas, entendidas como "Estado em ação", representam o Estado implantando 
um projeto de governo, sendo responsabilidade do Estado, ainda que tenha sido construída com a sociedade civil (HOFLING, 2001).

Desse modo, o Fórum da Produção Familiar de Santarém, como ficou denominado o conjunto de instituições articuladas em defesa da agricultura familiar, tornou-se atuante em diversas frentes conjunturais daquele momento, como por exemplo, a criação de um Grupo de Trabalho, proposto nas discussões do Fórum para coordenar e executar um processo de sensibilização e de criação da Reserva Extrativista Tapajós Arapiuns, já citada anteriormente.

Este Grupo de trabalho envolveu praticamente as mesmas instituições integrantes do Fórum da Produção Familiar. No entanto, estes diversos acontecimentos, apesar de importantes, conduziram objetivos bem específicos e provavelmente foram fatores que, na opinião do ex-presidente sindical, parasse de funcionar de um modo mais ampliado, devido a formação de novas articulações. Isso ocorreu, segundo ele, no ano de 2000, pois como relembrou, em seguida à criação da Organização das Associações da Reserva Extrativista Tapajós e Arapiuns. Esta instituição recebe o nome fantasia de TAPAJOARA e trata de uma organização legalmente constituída de abrangência intercomunitária e representativa dos moradores da Resex Tapajós/Arapiuns (MMA/ICMBio, 2014).

O Grupo de Trabalho RESEX Tapajós Arapiuns se transformou em um grupo de Apoio, já que segundo o ex-dirigente sindical, "esta Reserva já tinha a sua organização e já ia caminhar com suas próprias pernas". A partir de então, no ano de 2000 , as discussões no Fórum foram diminuindo sua regularidade, pois continua ele, "de lá pra cá, as instituições se reúnem sempre, mas não existe mais esse colegiado (grupo mobilizado de instituições), denominado Fórum".

Destacamos, ainda, que a ampliação na abrangência ocorreu a partir da condução do processo de articulação por uma instituição não governamental que passou, naquele momento, a presidir as ações do Fórum da produção Familiar. Na reestruturação, passou então a ser intitulado "Fórum da Produção Familiar do Baixo Amazonas Paraense", contemplando, portanto, nova área de abrangência, conforme ilustrado na

Figura 1:

Figura 1 - Mapa de localização do Território Baixo Amazonas - Oeste Paraense

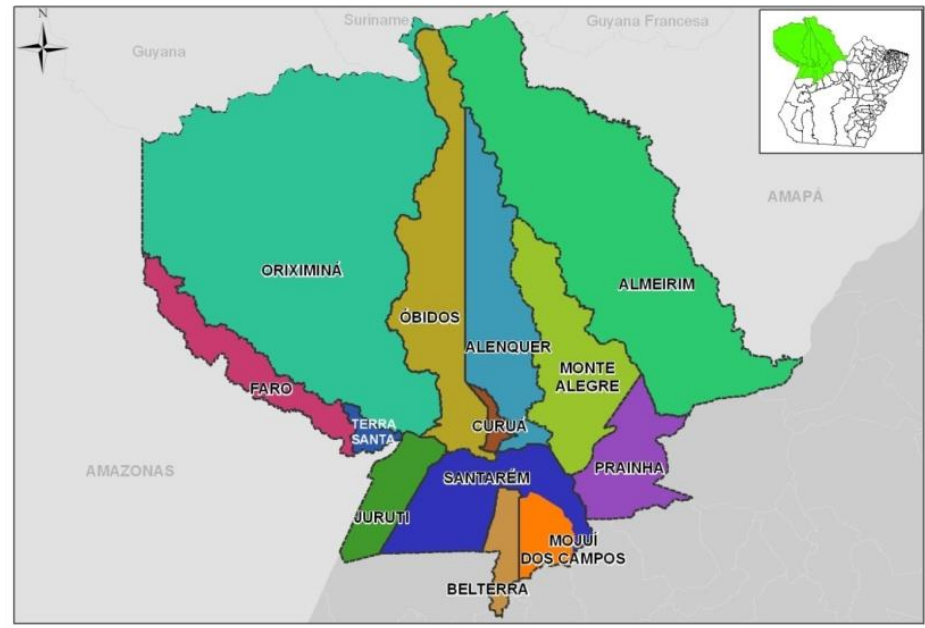

Fonte: Plano Territorial de Desenvolvimento Rural Sustentável - PTDRS-BAM, IPAM, 2011. 
No final da década de 1990, uma Ong, conduzindo as ações do Fórum-BAM, "assume um compromisso institucional de articulação para a implantação das Casas Familiares Rurais" nesta região do Baixo Amazonas, conforme informado em monografia de M. J. Alves (2013, p.15-16). Informa ainda a autora que em 2003, esta instituição elaborou um "Programa de Formação Alternativa Integral para Jovens do Baixo Amazonas" desenvolvendo um "Projeto de Acompanhamento Pedagógico das CFRs" nesta região, com ações de articulação e mobilização para a criação das Associações das Famílias em (10) dez municípios ${ }^{17}$, sendo criadas comissões de articulação destas CFRs em outros (04) quatro ${ }^{18}$. Naquele ano, os municípios de Santarém, Alenquer e Curuá já possuíam turmas em funcionamento (ALVES, 2013, p.15-16).

Podemos concluir que, somados aos fatos já relatados sobre a articulação à criação e consolidação da Resex Tapajós/Arapiuns, outro provável elemento explicativo, foi a incorporação das ações deste Fórum às ações de uma única instituição como estratégia regional, ainda que a instituição coordenadora tivesse a mesma abrangência em sua área de atuação. Deste modo, acreditamos que involuntariamente, ocorreu um certo distanciamento entre as demais instituições componentes daquele Fórum, diante da integração de ações institucionais específicas, o que supostamente contribuiu para a desarticulação do Fórum da Produção Familiar do Baixo Amazonas.

\section{O conceito de Território: espaço concreto e "campo de forças"}

Para melhor compreensão dos temas que abordaremos a seguir, achamos necessária uma breve definição do conceito de território, com apoio nos estudos da Geografia, entendendo que este é um conceito que interessa a muitas ciências. E no caso específico desta pesquisa, a noção de território ajuda no entendimento da implantação da Casa Familiar Rural de Santarém, a partir da delimitação do espaço de poder no debate das políticas de educação do campo no Baixo Amazonas.

O Território é um dos principais e mais utilizados termos da Geografia, pois está diretamente relacionado aos processos de construção e transformação do espaço geográfico. A Geografia Política tradicional definiu o território como o espaço concreto em si, apropriado por um determinado agente ou grupo social. A noção de apropriação empregada neste conceito ilustra a existência de uma relação de poder construída pelo homem sobre um espaço delimitado.

Um dos pioneiros na elaboração e sistematização do conceito de território foi o geógrafo alemão Friedrich Ratzel (1844-1904), fundador da geografia política, disciplina da ciência geográfica. Em sua análise, a apropriação duradoura, perene do território, relacionada ao poder e domínio exercido pelo Estado nacional, é capaz de construir vínculos e identidades, de forma que um povo que nele vive não possa mais ser compreendido, sem seu território, sua expressão territorial; pois tais identidades estariam ligadas aos atributos do espaço ocupado. (SOUZA, 2003)

A renovação crítica do pensamento geográfico propôs uma interpretação do conceito de território mais ampla que a da geografia clássica. Atualmente, diferentemente das concepções anteriores, o território pode se manifestar em múltiplas escalas, possuindo não necessariamente um caráter político, mas como um espaço delimitado pelo uso de fronteiras - nem sempre visíveis -consolidado a partir de uma expressão e imposição de poder.

Para Marcos Aurélio Saquet (2007, p. 68) “o território designa uma porção do espaço geográfico sob a jurisdição de certos povos, (...) a partir de comportamentos geopolíticos e psicológicos". Este autor também concebe o território como produto das 
relações humanas em sociedade, sendo a territorialidade humana o conjunto de estratégias adotadas pelos indivíduos no processo de apropriação e constituição dos territórios.

Destacamos também a concepção polissêmica de território proposta por Haesbaert da Costa (2006), a partir da abordagem "materialismo-idealismo". Este autor qualifica como perspectiva materialista: a política, a econômica e a natural. i) A Política, onde o território é visto como espaço delimitado onde se exerce uma relação de poder; ii) A Econômica, onde a dimensão espacial das relações econômicas é enfatizada e, iii)Naturalista,onde o território é visto a partir da relação do comportamento "natural" dos homens em relação ao meio físico. Quanto à perspectiva idealista, é qualificada como a perspectiva cultural ou simbólica do território, interpretado como fruto da apropriação ou valorização simbólica do espaço vivido por um grupo social.

Podemos compreender que o território possui vários níveis, do local ao global. Além disso, ele pode se expressar através de relações naturais ou biológicas, culturais, políticas, sociais, econômicas, militares, entre outras. Mas a conceituação mais comumente adotada o relaciona ao espaço apropriado e delimitado a partir de uma relação de poder como vimos nas diversas concepções de território em Souza (2003), Saquet (2007) e Haesbaert da Costa (2006).

Neste trabalho partilhamos da concepção teórica de territorialidade humana estratégica de Saquet (2007), conjugada com a visão integradora de território, enunciada por Haesbaert Costa (2006), por concordarmos que no caso da proposta de gestão territorial do Baixo Amazonas, construído pelo movimento social junto à proposta do governo federal "Território da Cidadania", abarca de um lado, a perspectiva materialista (política, econômica e natural), e de outro, a perspectiva idealista (cultural ou simbólica) do território. Deste modo, esta conceituação atende questões que integram tanto a dimensão material quanto a dimensão simbólica como partes inseparáveis deste conceito, presente nos acontecimentos analisados a seguir.

\section{A política pública fortalecendo o movimento social do campo: "Territórios da Cidadania"}

Feita esta breve incursão para explorar o termo território, nos reportamos à conceituação territorial como política de educação do campo, inserida como dinâmica de uma política de desenvolvimento denominada "Territórios da Cidadania", programa específico do Ministério do Desenvolvimento Agrário (MDA), sendo criado ainda em 2003, no Governo Lula, por meio de uma Comissão de Instalação das Ações Territoriais (CIAT).

Esta Comissão, criada por este Ministério através da Secretaria de Desenvolvimento Territorial (SDT), teve objetivo de preparar os caminhos e consolidar os territórios rurais das regiões do nosso país. Percebemos nas falas das lideranças da época que esta política, inicialmente não tinha identificação com o movimento social regional, que por sua vez, já se encontrava fragilizado com a desarticulação de seus membros.

A partir de 2008, é implantado pelo governo federal no Programa "Territórios da Cidadania", o CODETER como Política de controle social das políticas implantada pelo governo federal, dentro das ações do MDA. Para tanto foram mobilizados 19 Ministérios e outros Órgãos do Governo Federal para a criação no Brasil de 60 (sessenta) Territórios da Cidadania em 2008, sendo 13 (treze) destes, na região norte. (MDA, "Programa Territórios da Cidadania, 2008).

Este colegiado foi, portanto, definido como: 
(...) um espaço de articulação, discussão, cooperação, planejamento, e deliberação de ações do território do Baixo Amazonas relativas ao sistema de produção familiar, a infraestrutura, a educação, a cultura, a saúde aos direitos humanos, garantindo, desta forma, o desenvolvimento sustentável das atuais e futuras gerações. (Art. 1. Regimento interno do CODETER, 2014).

Desde que foi criado e formalizado no ano de 2008, sua trajetória previa, dentre outras perspectivas, o envolvimento dos órgãos governamentais e maior participação da sociedade civil na concepção de ser um "espaço de articulação, discussão, cooperação, planejamento, e deliberação de ações para o territorial sustentável". (CODETER, Relatório em 12.03.2015).

Este Colegiado Territorial, segundo recomendações oficiais do governo federal da época (2008), teria que ter a composição de representantes das três esferas de governo e da sociedade em cada território, com a indicação deste Programa de que a sua composição devesse ser ampliada em relação ao que eram os colegiados de então, além de ter uma coordenação executiva, bem como a paridade na sua composição ${ }^{19}$. (MDA, "Programa Território da Cidadania”, 2008).

Pudemos constatar que o Movimento Social do Campo em Santarém foi gradativamente se rearticulando com a implantação deste colegiado interinstitucional denominado Conselho de Desenvolvimento do Território do Baixo Amazonas (CODETER/BAM) ainda que na sua origem tenha se instituído por iniciativa governamental. Configurando-se atualmente no único espaço ampliado de debates sobre o desenvolvimento da região do Baixo Amazonas. Enquanto que a discussão sobre as Casas Familiares Rurais do Baixo Amazonas passou a partir de então, a ser pauta nas discussões de políticas públicas dentro deste espaço de articulação regional.

O CODETER, apesar de ter sido criado partindo de uma concepção oficial de "territórios rurais", agrupando municípios unidos pelo mesmo perfil econômico e ambiental, com identidade, coesão social e cultural semelhantes; no entanto ao reconhecer a existência anterior nos territórios de uma organização interna própria (fóruns de debate, colegiados), que já vinham trabalhando num Plano de Desenvolvimento, ao propor que os territórios rurais se transformariam nos "Territórios da Cidadania", foi adotado pelo movimento social, como possibilidade de fazer o debate das políticas públicas do campo no Baixo Amazonas.

Percebemos então, a partir de alguns depoimentos, que houve uma transição entre a execução e posterior enfraquecimento de uma política pública para gradativamente, ressurgir a construção de um espaço de articulação da sociedade civil. Assim, observamos que o movimento social do campo, inicialmente, se fez desconectado nesta política, deixando visível a falta de aproximação ou identificação com o povo. Pois neste Programa de infraestrutura rural, este Conselho Territorial, poderia decidir por elaborar uma proposta na forma de projeto como forma de acessar o recurso. Estes recursos do MDA para o CODETER ainda existem, segundo lideranças do movimento social, os quais incluem projetos aprovados que foram implantados no Baixo Amazonas (no ano de $2007^{20}$ ), no qual beneficiou as CFRs com a aquisição de equipamentos.

No entanto, ainda que o movimento social relacionado à articulação do CODETER, careça de uma relação mais orgânica, há de se reconhecer nesta atuação recente um potencial participativo do debate das políticas públicas do campo, incentivadas pelo caráter mobilizador existente nesta articulação. Pois conforme anunciado em seus objetivos "o 
fortalecimento das redes sociais de cooperação" é um dos seus desafios metodológicos, registrados na plenária composta pelas instituições integrantes deste Colegiado. Além de ser um dos seus desafios organizacionais a "integração das CFRs na reflexão territorial", apresentada em Relatório deste Colegiado (12.03.2015), como tarefa de "reforçar as articulações institucionais através de seus espaços de discussão locais, desta forma possui em sua concepção incentivando a participação de mais entidades".

\section{Considerações Finais}

No debate sobre as políticas públicas educacionais no país, é ainda perceptível a distância entre legislação e realidade das lutas sociais, sobretudo do campo. Ainda assim, o movimento social do campo teve importantes conquistas que materializam suas lutas na adoção de reivindicações sociais do campo como políticas públicas. E que apesar de serem insuficientes e apresentarem dificuldades de execução, um conjunto de Programas- como PRONERA $^{21}$, Programa Saberes da Terra e o Procampo ${ }^{22}$ - correspondem a acúmulos de lutas do Movimento da Educação do Campo.

Ao observarmos as dinâmicas territoriais da região do BAM e as principais interações entre as políticas públicas e os movimentos sociais em torno da agricultura familiar e do desenvolvimento do campo, reconhecemos o CODETER como espaço público de mobilização da sociedade, capaz de pressionar o Estado para o atendimento às necessidades do campo, em especial, à educação do e no campo. Relembrando que o CODETER se constitui atualmente no único espaço colegiado de governança territorial que busca mobilizar as representações dos diferentes entes federativos e da sociedade para a discussão do desenvolvimento territorial sustentável; funcionando também como espaço de controle social e proposição de políticas públicas.

Nesse colegiado a educação do campo representa uma bandeira de luta dos movimentos sociais que compõe os eixos de desenvolvimento rural sustentável e se fundamenta na ideia de construção da nova pedagogia que possa, além de contemplar a realidade do campo na estratégia de educação, contribuir também para fortalecer a agricultura familiar através do engajamento crítico dos jovens e de sua atuação qualitativa na unidade de produção familiar.

Deste modo, mesmo considerando as questões colocadas anteriormente, este espaço, do ponto de vista das organizações, se revelou gradativamente, ser de caráter participativo e dinâmico integrando: associações, sindicatos de trabalhadores e trabalhadoras rurais, colônia de pescadores, federações, entidades de assistência técnica, de fomento e de pesquisa, centrais sindicais, organizações governamentais e não governamentais (ONGs) que se identificaram neste colegiado de articulação de desenvolvimento regional. Buscando a constituição de espaços que traduziram e traduzem uma vontade de promover a participação na decisão pública, conforme identificado nos processos de construção das políticas públicas nestes últimos anos.

Consideramos, portanto com base no exposto nesta seção, que a história do movimento social do campo em Santarém, bem como no Baixo Amazonas, ao qual está incluída a articulação das CFRs, especificamente a de Santarém, é marcada por contradições de um movimento, presente no seu processo de articulação-desarticulaçãorearticulação associando elementos da conjuntura política atual, na qual a relação entre a sociedade civil e o Estado, também se transforma. Deste modo, no início da mobilização social, as instituições buscam uma aproximação, em uma fase intermediária, se afasta e se isola e se desarticula, para em seguida se articular, em um momento inverso (da política pública para o movimento social), no qual o Estado, por meio dos "Territórios da 
Cidadania" propõem um Colegiado, abrindo caminho e possibilidades, com a "desordem" de sua proposta, para novamente o movimento social se reorganizar.

Ao buscar compreender o processo histórico de mobilização social para a criação da CFR-STM, ao reconstituirmos os antecedentes da criação desta Casa, enfocamos o desenvolvimento histórico de estruturação do movimento social em Santarém. Deste modo, concluímos que as primeiras discussões por dentro das organizações das pastorais na década de 1980, ligadas à Igreja Católica, passando pela mobilização de Fóruns ligados à produtores familiares, representaram espaços fundamentais nos quais germinaram iniciativas do movimento social para a educação do campo na região, no caso específico das CFRs do Baixo Amazonas Paraense. o processo de mobilização das organizações sociais e de sua relação com o poder estatal, analisando as primeiras iniciativas de articulação interinstitucional, podemos concluir que a proposta da CFR, integrou uma estratégia de articulação territorial e constituição do poder local e regional do movimento social do campo. Acreditando que a educação dos sujeitos do campo se constitui em estratégia política e econômica na construção de melhorias nas condições de vida das pessoas do campo e de desenvolvimento local.

Como já destacamos, a história do movimento social e das CFRs se amplia regionalmente para o Baixo Amazonas Paraense, mas não deixa de ser marcada por contradições próprias de um movimento dialético que alterna momentos de articulaçãodesarticulação-rearticulação. Associando elementos que transformaram o debate e a relação entre a sociedade civil e o Estado, em uma situação paradoxal, na qual ao mesmo tempo em que defendem a Pedagogia da Alternância como política pública, criam um distanciamento com o Estado ao esquivar-se da gestão estatal.

De modo que, a história da CFR-STM, integra e se confunde com a história do movimento social do campo em Santarém e Região Oeste Paraense. E que, por meio da sua capacidade criativa, este movimento, ainda que no risco iminente de desestruturação, se apropria de uma política do Estado e gradativamente, ressurge como um espaço de articulação da sociedade civil, em uma estratégia conceituação de territorialidade e de resistência.

\section{Referências}

ALVES, M. J. F. Casa Familiar Rural de Santarém, perspectivas e desafios: um estudo de caso no Município de Santarém, Para. Monografia (Especialização) - Universidade Federal do Oeste do Para, Santarém. 2013.

ALENTEJANO. P. R. R. A política de assentamentos rurais do governo FHC e os desafios da reforma agrária no Brasil do século XXI. Revista Agrária, n. 1, pp. 2-15. Universidade Estadual do Rio de Janeiro, RJ, 2004.

ARCARFAR/PARÁ. CASA FAMILIAR RURAL DE SANTARÉM. Projeto Político Pedagógico: Uma construção coletiva da CFR-Stm. Santarém, PA, 2009. Digitado.

CASA FAMILIAR RURAL DE SANTARÉM. Relatório de Atividades Anual da Casa Familiar Rural de Santarém. Santarém, PA, 2014. Digitado.

ARCAFAR/PA. Acesso em 12.01. 2016 arcafarpara.blogspot.com.br

BENTES. Antonio José Mota. Pedagogia da Alternância em Santarém. Santarém, 2015, Sem notas tipográficas (snt).

BRANDÃO, Carlos Rodrigues. A educação como cultura. Campinas/ São Paulo: Mercado de Letras, 2002. 
CADERNO DE ANOTAÇÕES. BENTES, Antonio José. Mota (org). Registro das reuniões da Área Pastoral n.04. Diocese de Santarém, na sede do Grupo de Defesa da Amazônia (GDA), Santarém, PA, em 12 de Dezembro de 1994, snt.

COLEGIADO DE DESENVOLVIEMNTO TERRITORIAL DO BAIXO AMAZONAS (CODETER/BAM). Relatório do Seminário de Educação do Campo realizado na sede do CEFTBAM, em 25 de abril de 2015.

. Regimento interno, 18.08.2014.

COLETI, Claudinei. Neoliberalismo e burguesia agrária no Brasil. Revista Lutas \& Resistências, Londrina, v.1, p.131-145, set. 2006

COSTA, Rogério Haesbaert da. O mito da desterritorialização: do "fim dos territórios" à multiterritorialidade. $2^{\mathrm{a}}$ ed. Rio de Janeiro: Bertrand Brasil, 2006.

DAGNINO, Evelina. Sociedade civil e espaços públicos no Brasil. São Paulo: Paz e Terra/UNICAMP, 2002.

FRIGOTTO, Gaudêncio. In: MST. Boletim da Educação. Educação no MST. Balanço 20anos, $n^{\circ} .9$ de dezembro de 2004. (Entrevista) (p. 65-68)

HÖFLING, E. M. Estado e políticas (públicas) sociais. Cadernos Cedes, ano XXI, $\mathrm{n}^{\circ}$ 55, novembro/2001 [p. 30-41].

INSTITUTO DE PESQUISA AMBIENTAL DA AMAZÔNIA (IPAM)- CIAT. Espaços e instrumentos de desenvolvimento territorial no Território Baixo Amazonas - PA, Santarém. Relatório de missão - 8 a 21 de fevereiro de 2009. (Versão preliminar não publicado)

. Plano Territorial de Desenvolvimento Rural Sustentável - PTDRS do Baixo Amazonas, Estado do Pará - Santarém, 2011. 66 p, snt.

MAGAlHÃES, Benedita Acidelma Coelho dos Santos. Educação do Campo, Poder local e Políticas Públicas: a Casa Familiar Rural de Gurupá-Pará, uma construção permanente. Dissertação (Mestrado em Educação) - Universidade Federal do Pará (UFPA), 2009.

MDA. TERRITÓRIO DA CIDADANIA Fonte: Sistema de Informações Territoriais (http://sit.mda.gov.br). http://www.territoriosdacidadania.gov.br/Acesso em Agosto de 2015.

NOSELLA, Paolo. Origens da pedagogia da Alternância. Coleção Educação do Campo: Edufes, Vitória, 2014.

RAFFESTIN, Claude. Por uma geografia do poder. Tradução de Maria Cecília França. São Paulo: Ática, 1993.

SAQUET, Marcos Aurélio. Abordagens e concepções sobre o território. $1^{\mathrm{a}}$. Ed. São Paulo: Expressão Popular, 2007.

SILVA, Lourdes Helena da. As experiências de formação de jovens do campo:alternância ou alternâncias? Viçosa, Minas Gerais: EFV, 2003

SOUZA, Marcelo José Lopes de. O território: sobre espaço e poder, autonomia e desenvolvimento. In CASTRO, Iná Elias de; GOMES, Paulo Cesar da Costa; Correa, Roberto Lobato (Orgs.). Geografia: conceitos e temas. Rio de Janeiro: Bertrand Brasil, 2003, p.77-116. 


\section{Notas}

${ }^{1}$ Mestre em Educação/UFOPA, Especialização em Educação Ambiental / FACINTER, Graduada em Ciências Sociais /UFPA- Campus Santarém/Pará.

${ }^{2}$ Doutorado e Pós-doutorado em Educação/FE-Unicamp. Professor Associado, Docente do Programa de Pósgraduação em Educação da Universidade Federal do Oeste do Pará/UFOPA. Líder do Grupo de Estudos e Pesquisas História, Sociedade e Educação no Brasil HISTEDBR/UFOPA.

${ }^{3}$ Pelo Movimento da Articulação Nacional por uma Educação do Campo Com a participação do Movimento dos Trabalhadores Rurais Sem Terra (MST), da Confederação dos Trabalhadores na Agricultura (Contag) e da Associação Regional das Casas Familiares Rurais (ARCAFAR).

${ }^{4}$ Sem notas tipográficas.

${ }^{5}$ Conselho de Desenvolvimento Territorial do Baixo Amazonasin Seminário de Educação do Campo, 25.04.2015.

${ }^{6}$ Datadas de seis e doze de dezembro de 1994, referentes aos encontros de áreas pastorais.

${ }^{7}$ Durante o período de 1997 a 1999.

${ }^{8}$ Três anos depois, no período de 24 a 26/08/1998 em um Centro de Formação da Igreja Católica "Emaús", foi realizado, também com a promoção deste Fórum, o II Seminário da Produção Familiar de Santarém com a participação de 88 pessoas representando órgãos, Universidades, entidades representativas e organizações não governamentais e instituições ligadas à igreja católica. Além da representação de associações de Produtores. (Relatório do II Seminárioda Produção Familiar de Santarém).

${ }^{9}$ Esta Comissão possivelmente conduziu a criação do "Fórum da Agricultura", antecedendo a criação do Fórum da Produção Familiar de Santarém.

${ }^{10}$ Este fato ocorrido em17 de abril de 1996 no município de Eldorado dos Carajás, no sul do Pará,resultou na morte de dezenove Trabalhadores do Movimento Sem-Terra pela Polícia Militar do Estado do Pará, na gestão do então governadorAlmir Gabriel. Em confronto com 1.500 sem-terra em marcha de protesto ao longo da rodovia BR-155, que liga a capital Belém, ao sul do Estado, contra a demora da desapropriação de terras. A ordem para esta ação policial partiu do Secretário de Segurança do Pará, Paulo Sette Câmara. Em19 de abril, oentão presidente Fernando Henrique Cardoso determinou o deslocamento de tropas do exército para a região para conter a escalada de violência, pedindo a prisão imediata dos responsáveis pelo massacre. Uma semana depois do massacre, foi confirmada a criação do Ministério da Reforma Agrária.Fonte: https://pt.wikipedia.org/wiki/Massacre de Eldorado dos Carajás. Acesso em 03.03.2016.

${ }^{11}$ Texto elaborado com apoio dos registros em caderno de notas (CADERNO) durante "Encontro de Coordenadores de projetos comunitários", coordenado pela organização não governamental de assessoria. Este encontro ocorreu no período de 03 a 06 de janeiro de 1995. Participaram 22 lideranças comunitárias de doze comunidades de regiões distintas do planalto e ribeirinha do Tapajós e Arapiuns.

${ }^{12}$ Este projeto era composto por uma linha de apoio de financiamento comunitário para aquisição de barco coletivo administrado pela associação em parceira com uma instituição não governamental de assessoria comunitária, desenvolvido até o ano de 1999, na região Tapajós e Lago Grande em Santarém.

${ }^{13}$ A denominação "Baixo Amazonas- BAM", se refere à uma divisão territorial localizada no oeste paraense que abrange os seguintes municípios: Alenquer, Almeirim, Aveiro, Curuá, Faro, Itaituba, Juruti, Monte Alegre, Oriximiná, Óbidos, Prainha, Santarém e Terra Santa.

${ }^{14} \mathrm{Com}$ o intuito de investigar a ligação do Sindicato com a proposta da CFR/Santarém, apoiamo-nos na memória do ex-presidente do STTR, devido sua experiência na direção deste Sindicato, como vice (1995 e 1996) e em seguida presidente por dois mandatos no período de 1997 à 2000.

${ }^{15} \mathrm{O}$ entrevistado referiu-se à Reserva Extrativista Tapajós/Arapiuns, já citada anteriormente.

${ }^{16}$ Refere-se à Unidade de Conservação de uso sustentável do município de Santarém, área de 677.513, 24 hectares, abrangendo mais de 60 comunidades das regiões dos rios Tapajós e Arapiuns, criada pelo Decreto s/n $\mathrm{n}^{\circ}$ de 06 de novembro de 1998 e fruto da mobilização de instituições comunitárias e não governamentais atuantes na região e apoio de órgãos federais, como CNPT/IBAMA.

${ }^{17}$ Almeirim, Aveiro, Curuá, Itaituba, Juruti, Monte Alegre, Oriximiná, Óbidos, Prainha e Terra Santa.

${ }^{18}$ Faro, Trairão, Jacareacanga e Belterra.

${ }^{19}$ São membros atuais do CODETER/BAM, as organizações que estão na área de abrangência deste Território, que oficialmente encaminharam os nomes para compor o colegiado, sendo elas governamentais, Não governamentais, representativas de trabalhadores rurais, associações comunitárias, Agências de fomento e bancárias, Universidades públicas e privadas (Artigo 2. Regimento interno do CODETER/BAM, 2014).

20SAGRI. Projeto 1334 - Desenvolvimento Sustentável de Territórios Rurais (PRONAT) Apoio a Projetos de Infraestrutura e Serviços de Infraestrutura, com objetivo de "fortalecer a Agricultura Familiar no Território do Baixo Amazonas através da estruturação de Casas Familiares Rurais e implantação de unidades de produção de fruticultura de Várzea e Terra Firme”. (Agosto a Dezembro de 2007) 


\footnotetext{
${ }^{21}$ Programa Nacional de Educação na Reforma Agrária

${ }^{22}$ Programa de Apoio às Licenciaturas em Educação do Campo

Recebido: novembro/16

Aprovado: dezembro/16
} 